\title{
Relationship Between Biological Control, Incidence of Hypovirulence, and Diversity of Vegetative Compatibility Types of Cryphonectria parasitica in France
}

\author{
Cécile Robin, Carole Anziani, and Paolo Cortesi
}

First and second authors: Unité de Recherches Santé Végétale, INRA Bordeaux, BP 81, 33883 Villenave d'Ornon, France; and third author: Istituto di Patologia vegetale, Università degli Studi di Milano, via Celoria 2, 20133 Milan, Italy. Accepted for publication 31 March 2000.

\begin{abstract}
Robin, C., Anziani, and C., Cortesi, P. 2000. Relationship between biological control, incidence of hypovirulence, and diversity of vegetative compatibility types of Cryphonectria parasitica in France. Phytopathology, 90:730-737.

In France, chestnut blight, caused by Cryphonectria parasitica, has been controlled since 1974 in orchards, but never in coppice forests, by releasing hypovirulent strains infected with CHV1 hypovirus. We tested the hypothesis that this biological control (BC) has lead to a decrease in blight severity, spread of hypovirulence, and change in $C$. parasitica populations. The low severity of chestnut blight was confirmed in the six regions studied (subdivided into zones). The remission of cankers was associated with the presence of white isolates presumed to be hypovirulent. These two parameters were also correlated, at the zonal level, to the frequency of sites where $\mathrm{BC}$ was used. However, the
\end{abstract}

ABSTRACT

estimates of the natural background level of hypovirulence, independent of $\mathrm{BC}$, ranged from $4 \%$ in forests in Dordogne to $60 \%$ in orchards in Lozère. Differences in the rate of hypovirulent isolates among regions were consistent with the diversity of vegetative compatibility (VC) types in populations of $C$. parasitica. The highest VC-type diversity and mean allelic diversity for known vegetative incompatibility (vic) genes were observed in Dordogne. We showed that the current diversity of VC types in populations of $C$. parasitica was lower than in 1981. We found $30 \mathrm{VC}$ types among 1,113 isolates of $C$. parasitica. Ten VC types were incompatible with known EU testers, suggesting that one additional vic gene or allele at one of the six vic loci known should be present in Europe.

Additional keywords: Castanea sativa, Endothia parasitica, epidemiology, population differentiation.
The hypovirulence caused by Cryphonectria hypoviruses (CHVs) on Cryphonectria parasitica (Murr.) Barr, the causal agent of chestnut blight, is an example of virus-mediated attenuation of pathogen virulence $(11,16,24,41)$. Infections by hypovirulent isolates result in superficial cankers on both European (Castanea sativa Mill.) and American ( $C$. dentata [Marsh] Borkh) chestnut trees, whereas virus-free isolates cause deep, lethal cankers. CHVs are cytoplasmic double-stranded RNA viruses that move into conidia, but not into ascospores, and can be transmitted from an infected isolate to a virus-free isolate through hyphal anastomosis. Hypovirulence offers great potential for biological control (BC) of chestnut blight as stated in 1965 by Grente (18) and reviewed later by several authors $(7,23,32,44,45)$. In France, the Ministry of Agriculture has promoted an intensive release of hypovirulent isolates for $\mathrm{BC}$ of chestnut blight on 180,000 ha since 1974. Today BC is still applied in orchards, especially in southeastern France and to a lesser extent in southwestern France (Dordogne and Corrèze), but never in coppice forests. BC was applied following Grente's protocol (20); in each district, up to eight hypovirulent isolates, selected according to the vegetative compatibility (VC) types present in the populations of $C$. parasitica $(19,20)$, were released. The selected mixtures of hypovirulent isolates were prepared by a private company and first applied by specialized technicians and later by growers. Every year in these orchards, all newly formed cankers are treated with hypovirulent isolates by introducing the mycelia

Corresponding author: C. Robin; E-mail address: robin@ bordeaux.inra.fr

Publication no. P-2000-0519-01R

(C) 2000 The American Phytopathological Society into holes in the margin of the canker. This treatment has a curative effect and favors the healing of the canker when the virus is successfully transmitted. BC may have a preventative effect depending on the spread of hypovirulent strains within the area where they were released. According to Grente, the percentage of healing cankers increased in orchards treated with BC (19) and a similar result was obtained in Italy (8). A better knowledge of the spread of hypovirulence is crucial to predict the efficacy of $\mathrm{BC}$ and the dynamics of blight incidence in chestnut ecosystems.

Although hypovirulent isolates with broad conversion capacities were found $(28,34)$, vegetative incompatibility restricts hypovirus transmission. The rate of transmission is negatively correlated with the number of vegetative incompatibility (vic) genes that differ between mycelia that anastomose $(2,25,31)$. The spread of CHVs should be directly correlated to the quantity and effectiveness of inoculum produced by hypovirulent isolates and to the population genetic structure for $\mathrm{VC}$ types. A high percentage of virus-infected isolates should be found in populations with low diversity of VC types, limiting chestnut blight severity. At the continental level, this scenario fits the lack of spread of hypoviruses in populations of $C$. parasitica in North America, characterized by high VC diversity $(4,5,32,41)$. By contrast, in Europe the low VC-type diversity favors the spread of hypovirulent isolates of $C$. parasitica and the recovery of European chestnut in many areas (22). In Switzerland, the rate of hypovirulent isolates of two fungal populations was associated with low VC-type diversity (10). However, few studies have associated diversity of $\mathrm{VC}$ types and spread of hypovirulence on a smaller scale, i.e., in different populations of $C$. parasitica. In France, spontaneous healing of cankers was reported recently by chestnut growers, suggesting possible local spread of hypovirulence. 
Hypovirus CHV1 is responsible for debilitation, reduced sporulation, and female sterility of infected strains $(3,11,18$, $44,47)$. Consequently, the spread of CHV1 in a fungal population may have a significant effect on the reproductive behavior of $C$. parasitica (35). Thus, the frequent release of hypovirulent strains for BC may cause a significant change in population structure for VC-type diversity, canker morphology, and proportion of white isolates. We tested the hypothesis that the regression of chestnut blight incidence due to $\mathrm{BC}$ has lowered the VC-type diversity found in France in 1981 as reported by Greute (19), the only study available. We also studied the distribution and diversity of VC types in populations of $C$. parasitica from the main chestnut growing areas of France.

\section{MATERIALS AND METHODS}

Study sites, sampling strategy, and $C$. parasitica isolation. C. parasitica was sampled from 1995 to 1997 in the most economically important chestnut-growing regions in France: $n$ orchards in Ardèche, South Corsica, Gard, and Lozère, in orchards and coppice forests in Languedoc-Roussillon, and in coppice forests in Dordogne. In Ardèche the chestnut cover was mostly continuous, whereas in the other regions all zones sampled were separated either by relief or other land-use patterns (Fig. 1). Zones LR-1, LR-2 and LR-3 were located in three districts, i.e., Aude,
Pyrénées Orientales, and Hérault, respectively. In each orchard, the history of $\mathrm{BC}$ was investigated by interviewing the grower to determine whether and when hypovirulent isolates were released for $\mathrm{BC}$. The intensity of $\mathrm{BC}$ in zones and regions was assessed based on the percentage of sites where BC was applied at least once (BCS). The $C$. parasitica isolates obtained in each zone were pooled to constitute the subpopulations, and the subpopulations of each region were pooled into one population per region. In each zone, $C$. parasitica was sampled from several chestnut sites, with an average distance of $5 \mathrm{~km}$ between sites. In each site, at least 10 evenly distributed blighted trees (neighbor trees were avoided as far as possible) were chosen, except in Dordogne where only 5 trees were chosen, and one canker per tree was sampled to avoid clones (38). Cankers that were treated with hypovirulent isolates were not sampled. Each canker sampled, except in Dordogne in 1996, was scored for morphology and was classified as active, healing, or healed. From each canker five bark samples, four from the edges and one from the middle, were removed with a cork borer ( $8 \mathrm{~mm}$ in diameter) and stored in a plastic tube until isolation. Bark samples were surface-disinfected for $15 \mathrm{~s}$ in $70 \%$ ethanol, rinsed in sterile water, blotted on filter paper, and placed on potato dextrose agar (PDA at 39g/liter, Difco Laboratories, Detroit). One isolate per canker was randomly chosen and transferred to PDA. To avoid bias by selecting isolates based on mycelium color, this was done before pigmentation occurred, i.e.,

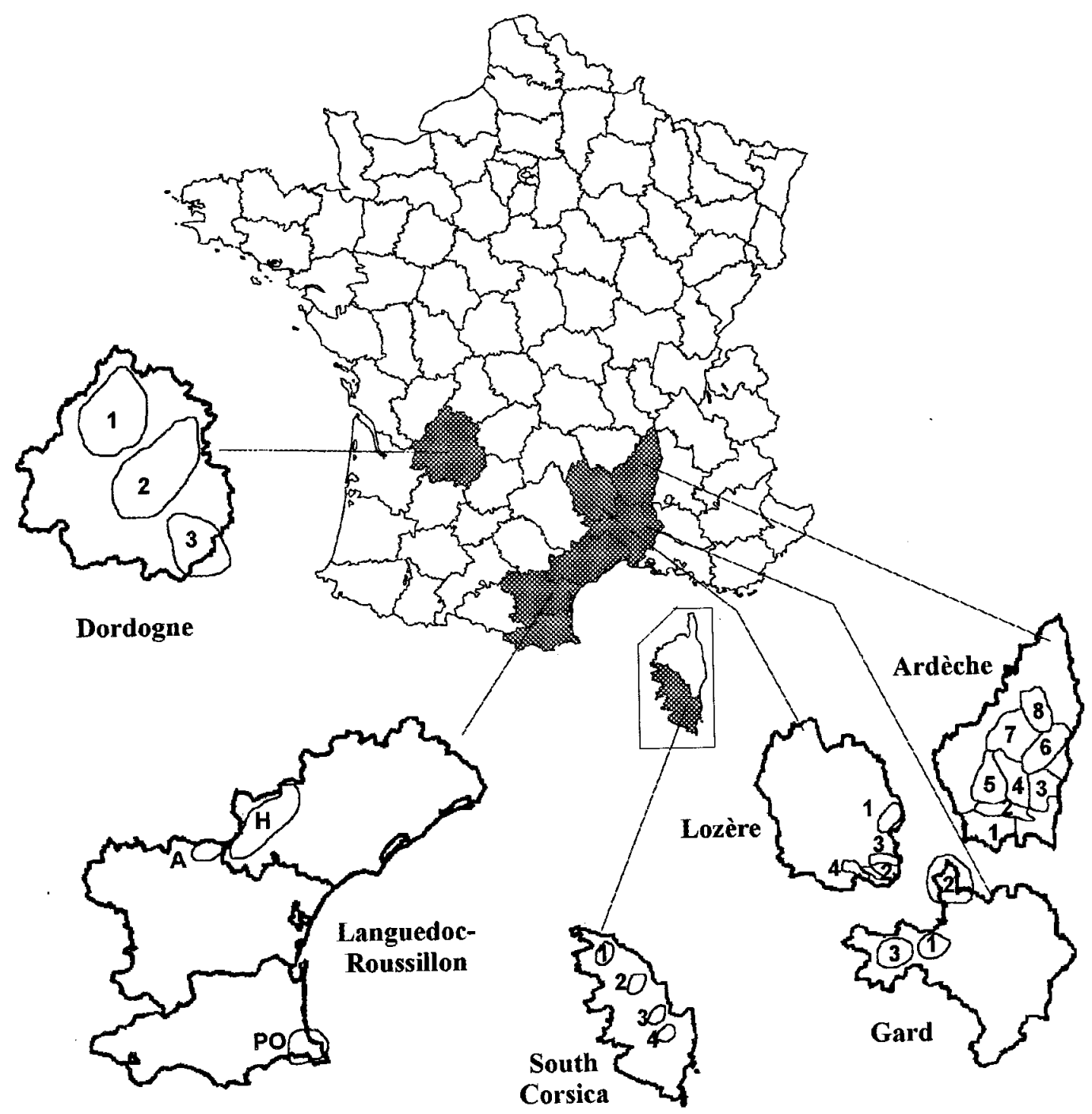

Fig 1. Regions and zones of France where Cryphonectria parasitica was sampled. 
after 3 days of incubation at $25^{\circ} \mathrm{C}$ in the dark. Mycelium color of each isolate was scored after 8 days of incubation at $25^{\circ} \mathrm{C}$ and a 16-h photoperiod. Isolates with a white phenotype were termed white, and were presumed to be infected with CHV1 $(11,16)$, whereas isolates with an orange phenotype were presumed to be virus-free. All isolates were stored in tubes on PDA slants at $6^{\circ} \mathrm{C}$.

VC and conversion tests. VC was evaluated on PDA supplemented with colorant, either amaranth (Sigma Chemical Company, St. Louis) or bromocresol green, sodium salt (Research Organics Inc., Cleveland, $\mathrm{OH}$ ) at a final concentration of 120 and $50 \mathrm{mg} / \mathrm{liter}$, respectively, to enhance the barrage reaction between incompatible isolates $(25,42)$. Small cubes of 7-day-old agarmycelium were paired $\approx 1 \mathrm{~mm}$ apart, $1 \mathrm{~cm}$ from the edge of a 9$\mathrm{cm}$ petri dish. Six pairings were made per petri dish. Dishes were incubated for 7 days in the dark at $25^{\circ} \mathrm{C}$, followed by 7 days incubation in daylight. Vegetative incompatibility was scored after 7 and 14 days of incubation. Isolates were considered incompatible when a barrage was observed between the two mycelia; they were considered compatible when the two mycelia merged completely (4). All isolates from each subpopulation were first paired in all combinations, and one isolate of each VC type was kept as a tester. The testers of all subpopulations were successively paired in all combinations to find the compatible $\mathrm{VC}$ types, and finally, one tester isolate for each VC type was paired, at least twice, against the set of 64 European testers (EU) $(13,15)$ and against the Swiss isolate $\mathrm{CH}-27$, named EU-65 by D. Rigling (Swiss Federal Institute for Forest, Snow, and Landscape Research, Birmensdorf, personal communication; Table 1). The pairings with testers EU-1 to EU-31 and EU-65 were performed in France, while in Italy the isolates found incompatible were paired on PDA (14) with all 65 EU testers. Conversion tests were conducted as previously described (19) by pairing each of the six hypovirulent CHV1-infected isolates used in France for BC (Table 1) with all EU testers for VC types found in the French population of $C$. parasitica. Change in the mycelium color of the EU testers, from orange to white, was taken as evidence of hypovirus transmission and conversion to hypovirulence.

Assessment and comparison of VC-type diversity. The Shannon index $\left(\mathrm{Hs}=\Sigma p_{i}\left(\ln p_{i}\right), \mathrm{I}=1, \ldots, \mathrm{S}\right.$, where $p_{i}$ is the frequency of the $i$ th VC type and $S$ is the number of VC types) was calculated for each population and subpopulation. This diversity index followed a normal distribution (33). A $t$ - test described by Hutcheson (26) allows the comparison of Shannon

TABLE 1. Origin of isolates of Cryphonectria parasitica used as vegetative compatibility testers and for biological control of chestnut blight

\begin{tabular}{ll}
\hline Isolates & Origin \\
\hline EU-1 to -31 & Cortesi et al. 1998 (15) \\
EU-32 to -64 & Cortesi and Milgroom 1998 (13) \\
EU-65 & D. Rigling: CH-27 Ollon, Vallais, Switzerland, 1997 \\
EU-66 & This study: MSD3, Fossemagne, Dordogne, France, 1995 \\
EU-67 & This study: MSA10, Pont de Beaume, Ardèche, France, 1995 \\
EU-68 & This study: MSA3, St. Clerge la Serre, Ardèche, France, 1995 \\
EU-69 & This study: MSA9, Chassiers, Ardèche, France, 1995 \\
EU-70 & This study : MSD14, St. Caprais, Dordogne, France, 1995 \\
EU-71 & This study: D15, Bourdeix, Dordogne, France, 1995 \\
EU-72 & This study: MSD5, Issac, Dordogne, France, 1995 \\
EU-73 & This study: MSD12, St. Laurent La vallée, Dordogne, France, \\
& 1995 \\
EU-74 & This study: D2, Firbeix, Dordogne, France, 1995 \\
2022 & Grente, Gonfaron, Var, France, hypovirulent, CHV1 infected, \\
& 1970 \\
2079 & Grente, Gonfaron, Var, France, hypovirulent, CHV1 infected, \\
& 1970 \\
2100 & Grente, Sablières, Corrèze, France, hypovirulent, CHV1 \\
& infected, 1975 \\
2103 & Grente, Castillon, Hautes Pyrénées, hypovirulent, France, \\
& CHV1 infected, 1975 \\
2113 & Grente, Ste. Fortunate, Corrèze, France, hypovirulent, CHV1 \\
& infected, 1975 \\
\hline
\end{tabular}

indices between two populations. The value of $t$ was calculated according to the formula

$$
t=\left(H s_{1}-H s_{2}\right) /\left(\operatorname{Var} H s_{1}+\operatorname{Var} H s_{2}\right)^{1 / 2} \text { with } \operatorname{Var} H s=\left[\Sigma p_{i}\left(\ln p_{i}\right)^{2}-\right.
$$
$\left.\left(\Sigma p_{i} \ln p_{i}\right)^{2}\right] / N-(S-1) /\left(2 N^{2}\right)$. The number of degrees of freedom (df) was calculated as

$$
\mathrm{df}=\left[\left(\operatorname{Var} H s_{1}+\operatorname{Var} H s_{2}\right)^{2} /\left[\left(\operatorname{Var} H s_{1}\right)^{2} / N_{1}+\left(\operatorname{Var} H s_{2}\right)^{2} / N_{2}\right] .\right.
$$

The method developed by Lewontin (29) to partition diversity into hierarchical and geographical components using the Shannon index was applied to our sample. The two hierarchical levels studied were zones and regions. Shannon diversity indices calculated for each zone, each region, and France, using the VCtype frequencies calculated for each subpopulation, each population, and for total sample, respectively. The total diversity was allocated to the between-region, between-zone, and withinzone components.

Using the vic genotypes (13) of the EU types found in France, allelic diversity for each vic locus and mean allelic diversities for each population were estimated as described by Milgroom and Cortesi (36).

\section{RESULTS}

Frequency of chestnut sites treated with $\mathrm{BC}$ and canker morphology. The frequency of $\mathrm{BC}$ was estimated in each region and zone (Table 2). In Gard, Lozère, and Ardèche, BC was applied regularly in a high percentage of orchards, i.e., more than $50 \%$. The first release of hypovirulent isolates dated back to 1978 in these regions. BC was applied at different frequencies within regions (e.g., in Ardèche). In Corsica and Languedoc-Roussillon, the percentage of BCS was lower, and BC was applied more sporadically than in the latter regions. The neglect of chestnut groves resulted in a low percentage of BCS in Cor-4. In Dordogne, the percentage of BCS was nil because BC is not applied in coppice forests.

In each zone, $C$. parasitica was isolated from 77 to $100 \%$ of cankers sampled. Isolation failure was higher for healed cankers than for active or healing cankers (results not shown). Only cankers yielding $C$. parasitica were retained for further analyses. In all regions, the percentage of cankers in remission (healing or healed) was higher than 30\% (Table 2). However, there were significant differences in the frequency of the three types of cankers among regions $\left(\chi^{2}=307.7, P<1 \%\right)$. The percentage of healed cankers was nil in Dordogne, $22 \%$ in Lozère, and less than $10 \%$ in the other regions. In Ardèche and Lozère, less than $30 \%$ of cankers were active whereas in Corsica, Languedoc-Roussillon, and Dordogne more than $60 \%$ of the cankers were active. The percentage of BCS in each zone was significantly correlated with the percentage of cankers in remission (Pearson coefficient: $R=$ $0.522, P<1 \%)$.

Recovery of white isolates. Altogether, $25 \%$ of the 1,113 isolates had a white phenotype. They were obtained from healed, healing, and active cankers (Table 3). In Ardèche and South Corsica a similar percentage of cankers yielded white isolates regardless of canker morphology. In Gard, however, a higher percentage of white isolates was obtained from healing or healed cankers. At the regional level, the percentage of white isolates varied significantly, from $4 \%$ in Dordogne to $11 \%$ in South Corsica, and $59 \%$ in Lozère (Table 2). At the zonal level, the percentage of white isolates was correlated with the percentage of $\mathrm{BCS}$ and the percentage of cankers in remission (Pearson coefficients; $R=0.584$ and 0.580 , respectively; $P<1 \%$ ). However, white isolates were found in two zones, Cor-4 and Dor-1, where hypovirulent isolates were not released (Table 2). Conversely, in Cor-3, where hypovirulent isolates had been released in three of 
five sites, only $7 \%$ of white isolates were recovered. On a finer scale, the percentages of white isolates in sites with $\mathrm{BC}$ and sites without BC were not significantly different (Fig. 2), except in Gard where a significantly higher percentage of white isolates was recovered in sites where hypovirulent isolates were released $\left(\chi^{2}=\right.$ 4.406, $P=3.6 \%$ ). Most of the white isolates belonged to VC types EU-2, EU-1, and EU-5. In our tests, the BC agents did not have a broad conversion capacity, each converting only two or three VC types.

Diversity of VC types in populations of $\boldsymbol{C}$. parasitica. The Shannon diversity index ranged from 2.05 for Dordogne to 1.11 for Corsica (Table 2). Among the 132 isolates from Dordogne, a total of $14 \mathrm{VC}$ types was detected, with the 4 most frequent types, EU-33, EU-2, EU-72, and EU-66, accounting for 31, 17, 12, and $10 \%$ of isolates, respectively (Fig. 3). In contrast, in Corsica, Gard, Lozère, and Languedoc-Roussillon EU-2 was gathered from 50 to $70 \%$ of the isolates, and only three VC types (EU-2, EU-1, and EU-5) were gathered from more than $81 \%$ of the isolates. In Ardèche, VC-type EU-2 represented $67 \%$ of the isolates, and VC types EU-65, EU-1, and EU-68 represented between 6 and $10 \%$ of the isolates. According to the $t$ - test performed on $H s$, the
Dordogne population was significantly different from all other populations $(t>6, P<1 \%)$, and the Corsican population was significantly different from the populations of Lozère $(t=2.50, P$ $<1 \%)$ and Gard $(t=1.96, P=5 \%)$. The partition of the Shannon diversity index into hierarchical components confirmed the differentiation at the regional level, as well as at the zonal level. The between-region, between-zone, and within-zone components accounted for $23.4,13$, and $66.3 \%$, respectively, of the total

TABLE 3. Percentage of cankers yielding white isolates of Cryphonectria parasitica in southeastern regions of France ${ }^{\mathrm{a}}$

\begin{tabular}{lccc}
\hline & \multicolumn{3}{c}{ Canker type } \\
\cline { 2 - 4 } Region & Active & Healing & Healed \\
\hline Ardèche & 23 & 21 & 13 \\
Corsica & 11 & 12 & 15 \\
Gard & 29 & 53 & 80 \\
Languedoc- Roussillon & 16 & 23 & 50 \\
Lozère & 50 & 62 & 60 \\
\hline
\end{tabular}

a In Dordogne, morphology of cankers was assessed only in 1995, and white isolates were not obtained.

TABLE 2. Characteristics of chestnut zones and regions studied in France and diversity of vegetative compatibility (VC) types of resident subpopulations and populations of Cryphonectria parasitica

\begin{tabular}{|c|c|c|c|c|c|c|c|c|}
\hline Zone & No. of sites & $\%$ of $\mathrm{BCS}^{\mathrm{a}}$ & $\%$ of $\mathrm{HC}^{\mathrm{b}}$ & No. of isolates & No. of VC types & $P^{\mathrm{c}}$ & $H s^{d}$ & $\%$ white $^{\mathrm{e}}$ \\
\hline Ard-1 & 6 & 75 & 77 & 56 & 4 & 0.77 & 0.78 & 39 \\
\hline Ard-2 & 5 & 80 & 69 & 49 & 5 & 0.74 & 0.85 & 20 \\
\hline Ard-3 & 3 & 33 & 76 & 29 & 5 & 0.59 & 1.03 & 3 \\
\hline Ard-4 & 4 & 100 & 83 & 37 & 4 & 0.78 & 1.00 & 27 \\
\hline Ard-5 & 5 & 40 & 76 & 44 & 4 & 0.39 & 1.26 & 2 \\
\hline Ard-6 & 4 & 50 & 95 & 39 & 4 & 0.72 & 0.88 & 21 \\
\hline Cor-1 & 5 & 20 & 30 & 46 & 4 & 0.70 & 0.89 & 9 \\
\hline Cor-2 & 5 & 40 & 44 & 49 & 3 & 0.49 & 0.77 & 16 \\
\hline Cor-3 & 5 & 80 & 40 & 41 & 5 & 0.66 & 0.98 & 7 \\
\hline Cor-4 & 5 & 0 & 41 & 45 & 5 & 0.56 & 1.07 & 11 \\
\hline Dor-1 & 12 & 0 & 42 & 51 & 9 & 0.35 & 1.20 & 10 \\
\hline Gard-2 & 6 & 83 & 53 & 41 & 6 & 0.44 & 1.70 & 34 \\
\hline Gard-3 & 6 & 75 & 49 & 52 & 8 & 0.31 & 1.50 & 25 \\
\hline LR-1 & 2 & 50 & 50 & 19 & 3 & 0.53 & 0.94 & 60 \\
\hline LR-2 & 4 & 50 & 50 & 32 & 4 & 0.38 & 1.32 & 6 \\
\hline LR-3 & 7 & 29 & 49 & 64 & 5 & 0.83 & 0.66 & 25 \\
\hline Loz-1 & 4 & 75 & 94 & 35 & 6 & 0.43 & 1.20 & 63 \\
\hline Loz-2 & 6 & 100 & 88 & 46 & 7 & 0.37 & 1.60 & 41 \\
\hline Loz-3 & 5 & 60 & 98 & 40 & 5 & 0.48 & 1.19 & 65 \\
\hline Loz-4 & 6 & 83 & 98 & 52 & 8 & 0.67 & 1.13 & 67 \\
\hline \multicolumn{9}{|l|}{ Region } \\
\hline Ardèche & 38 & 53 & 55 & 360 & 10 & 0.68 & 1.18 & 21 \\
\hline
\end{tabular}

a Number of sites where biological control of chestnut blight was applied (BCS).

b Percentage of healing or healed cankers (HC).

${ }^{c}$ Frequency of the most common VC type.

d Shannon index for VC type diversity.

e Percentage of white isolates of C. parasitica. 
diversity. When the population of Dordogne was omitted, the estimates of the three components were 6, 10.6, and $85.3 \%$, respectively. On average, about six VC types were detected per subpopulation (Table 2). In 15 subpopulations of 25 , the dominant VC type included more than $50 \%$ of the isolates. Because of the differentiation of $C$. parasitica between regions, the relationship between the spread of white isolates and the diversity of $C$. parasitica subpopulations, as measured by the Shannon index,

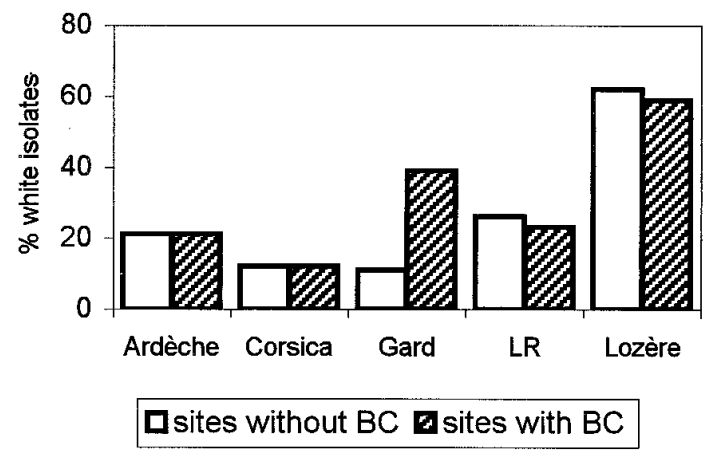

Fig. 2. Distribution and frequency of vegetative incompatibility types of Cryphonectria parasitica in six regions of France. was not analyzed across the 25 zones but was examined per region. Within each region, except Languedoc-Roussillon, the percentage of white isolates decreased as diversity increased. In Ardèche, the Pearson correlation coefficient between $H s$ and percentage of white isolates was significantly negative $(R=-0.81$, $P<1 \%)$. In the other regions, the number of zones was too low to calculate the correlation coefficient.

In 1981, $20 \mathrm{VC}$ types had been reported among the 138 isolates collected in 18 French districts $(5,19)$. Among these VC types, VC types U.S. VC-12, VC-40 and VC-56, which are compatible with EU-2, EU-5, and EU-12, respectively $(13,15)$, represented 3, 14 , and $1 \%$ of the isolates, respectively (S. L. Anagnostakis, Connecticut Agricultural Experiment Station, New Haven, personal communication). Of 138 isolates, 7 were from Dordogne, 10 from Ardèche, 6 from Corsica, 10 from Gard, 7 from Lozère, and 9 from Hérault. When these 49 isolates were pooled, and 12 VC types were identified, VC types EU-2 and EU-5 represented 4 and $22 \%$ of the isolates, respectively, and $H s$ was 2.24 . To compare previous results to ours, 10 subsets of 49 isolates were randomly drawn from our total sample, with the same number of isolates pooled per district studied as in Grente's study (19). In the 10 subpopulations sampled, the number of VC types varied from 8 to 12 , and the mean frequency of $\mathrm{VC}$ types EU-2, EU-1, and EU-5 was $58.4,14$, and $6.1 \%$, respectively. The Shannon diversity index varied from 1.31 to 1.63 , with a mean value of 1.46 , lower

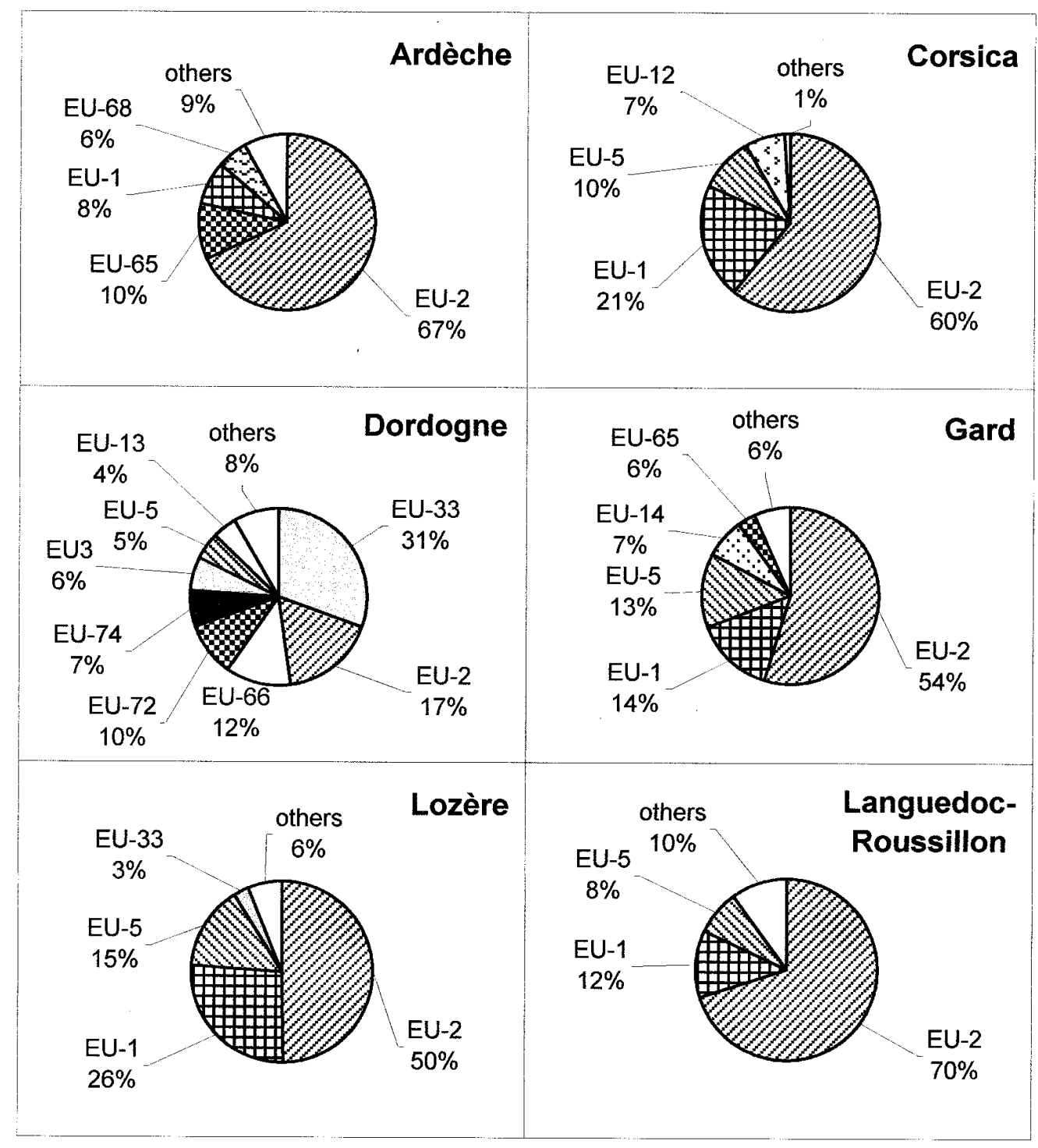

Fig. 3. Percentages of white isolates of Cryphonectria parasitica obtained from sites where biological control of chestnut blight was or was not applied. 
than the 2.24 diversity index calculated for the population sampled in 1981 .

When all 1,113 isolates were pooled, 30 VC types were detected in C. parasitica populations in France (Table 4). Eighteen were assigned to VC types already described in Europe, and two, EU-33 and EU-38, were found for the first time in the field. Nine new VC types, i.e., VC types different from all $65 \mathrm{EU} \mathrm{VC}$ types, were named with numbers higher than 65 (Table 1) and, so far, have been found only in France. Among them, five VC types, EU66, EU-70, EU-71, EU-73, and EU-74, were detected only in Dordogne, and three, EU-67, EU-68, and EU-69, only in Ardèche, whereas EU-72 was present in Dordogne and LanguedocRoussillon. Two new VC types, EU-69 and EU-73, were represented by one isolate (Table 4), whereas the others consisted of several isolates from different sites within the region. The VC types EU-67 and EU-68 were represented by orange and white isolates and EU-69 only by a white isolate. In the whole sample, the most common VC type was EU-2, accounting for 56\% of the isolates sampled. EU-1 and EU-5 were the second and third most common types, accounting for 13 and $7 \%$ of the isolates,

TABLE 4. Distribution of vegetative compatibility (VC) types of Cryphonectria parasitica in France

\begin{tabular}{|c|c|c|c|c|c|}
\hline \multirow{2}{*}{$\begin{array}{l}\text { VC } \\
\text { type }\end{array}$} & \multirow{2}{*}{$\begin{array}{c}\text { Converted by } \\
\text { hypovirulent isolate }^{a}\end{array}$} & \multicolumn{2}{|c|}{ Isolates of $C$. parasitica } & \multicolumn{2}{|c|}{ White isolates } \\
\hline & & Number & $\%$ & $\overline{\text { Number }}$ & $\%$ \\
\hline EU-2 & 2,022 & 622 & 55.8 & 185 & 65.8 \\
\hline EU-1 & 2,079 & 154 & 13.8 & 46 & 16.4 \\
\hline EU-5 & 2,079 & 79 & 7.1 & 23 & 8.2 \\
\hline EU-33 & 2,113 & 47 & 4.2 & 3 & 1.1 \\
\hline EU-65 & & 44 & 4.0 & & \\
\hline EU-12 & 2,100 & 29 & 2.6 & 5 & 1.8 \\
\hline EU-68 & 2,103 & 20 & 1.8 & 5 & 1.8 \\
\hline EU-14 & 2,022 & 16 & 1.4 & 6 & 2.1 \\
\hline EU-66 & 2,103 & 16 & 1.4 & & \\
\hline EU-72 & & 14 & 1.3 & & \\
\hline EU-67 & & 11 & 1.0 & 1 & 0.4 \\
\hline EU-74 & 2,113 & 9 & 0.8 & & \\
\hline EU-3 & & 8 & 0.7 & & \\
\hline EU-13 & & 6 & 0.5 & & \\
\hline EU-24 & & 6 & 0.5 & & \\
\hline EU-11 & & 4 & 0.4 & 2 & 0.7 \\
\hline EU-18 & & 4 & 0.4 & & \\
\hline EU-25 & & 4 & 0.4 & 1 & 0.4 \\
\hline EU-38 & 2,113 & 3 & 0.3 & 1 & 0.4 \\
\hline EU-4 & & 3 & 0.3 & 1 & 0.4 \\
\hline EU-30 & & 2 & 0.2 & 1 & 0.4 \\
\hline EU-70 & & 2 & 0.2 & & \\
\hline EU-71 & & 2 & 0.2 & & \\
\hline EU-9 & 2,100 & 2 & 0.2 & & \\
\hline EU-10 & & 1 & 0.1 & & \\
\hline EU-16 & & 1 & 0.1 & & \\
\hline EU-17 & 2,100 & 1 & 0.1 & & \\
\hline EU-29 & & 1 & 0.1 & & \\
\hline EU-69 & 2,022 & 1 & 0.1 & 1 & 0.4 \\
\hline EU-73 & & 1 & 0.1 & & \\
\hline Total & & 1,113 & 100.0 & 281 & 100.0 \\
\hline
\end{tabular}

${ }^{a}$ Conversion to hypovirulence was tested with the hypovirulent strains listed in Table 1 and by the methods described in text. respectively. The remaining $27 \mathrm{VC}$ types did not account for more than $5 \%$ of the isolates, and 6 were represented by a single isolate. White isolates of $C$. parasitica were distributed in 13 of the 30 VC types found (EU-1, EU-2, EU-5, EU-11, EU-12, EU-14, EU25, EU-30, EU-33, EU-38, EU-67, EU-68, and EU-69). Each of the hypovirulent strains used for BC in France converted two or three VC types (Table 1). All together, $85 \%$ of the isolates could be converted by at least one hypovirulent strain (Table 4).

Allelic diversities were calculated for the six populations using only the VC types with a known vic genotype (Table 5). Allele 2 at vic 3 is rare since it is present only in three $\mathrm{VC}$ types, EU-10, EU-33, and EU-38, resulting in the lowest mean gene diversity. The VC types EU-10 and EU-38 were both found in Ardèche but were represented by only 4 isolates, whereas EU-33 was represented by 2,5 , and 40 isolates in Gard, Lozère and Dordogne, respectively. Mean allelic diversities ranged from 0.384 in Dordogne to 0.081 in Ardèche. The Dordogne population had six polymorphic loci whereas in southeastern populations the number of polymorphic vic loci varied from two to five. In these populations, a high percentage of isolates belonged to VC-type EU-2, which has only one vic gene that is different from $\mathrm{VC}$ types EU-1, EU-4, and EU-14 and two vic genes different from VC-type EU-5. Recombination between these types would not give an important increase in allelic diversity for vic loci. In contrast, in Dordogne the two most common VC types, EU-33 and EU-2, differed by four vic genes, therefore sexual reproduction can result in 14 additional VC types.

\section{DISCUSSION}

Our study provides the first assessment of chestnut blight severity in France. We assessed morphology and spread of hypovirulence as measured by the percentage of white isolates of C. parasitica, which are highly, but not always, associated with hypovirulence (23). As expected, healed cankers yielded white isolates, with a frequency ranging from 13 to $80 \%$. However, white isolates were also recovered from 11 to $50 \%$ of active cankers in all regions, except Dordogne. These results may be due to our sampling method, which retained only one isolate from each canker, or to the coexistence of multiple isolates in cankers (10). The percentage of cankers in remission and the percentage of white isolates were correlated to each other, suggesting that the decrease in chestnut blight severity was associated with the spread of hypovirulence. Moreover, both percentages were correlated to the frequency of sites where $\mathrm{BC}$ was applied, suggesting that the spread of hypovirulence is associated with the use of BC. However, the proportion of converted isolates in the southeastern regions was larger than $80 \%$. In zones Ard-3, Ard-5, and LR-2, white isolates were found at a low frequency in spite of a high percentage of BCS (greater than $30 \%$ ). Furthermore, there was no difference in the frequency of white isolates recovered in sites with or without $\mathrm{BC}$ in each region, except in Gard. These results suggest that the hypovirus released for BC had a limited spread in the field in France, as reported previously in the United States (32).

The restriction fragment length polymorphism markers developed by Alleman et al. (1) to study the diversity of CHV1

TABLE 5. Allelic diversities at six vic loci in populations of Cryphonectria parasitia

\begin{tabular}{|c|c|c|c|c|c|c|c|c|c|}
\hline Population & $\begin{array}{c}\text { Number of } \\
\text { isolates }\end{array}$ & vic 1 & vic 2 & vic 3 & vic 4 & vic 6 & vic 7 & Mean & $\begin{array}{c}\text { Number of } \\
\text { polymorphic loci }\end{array}$ \\
\hline Ardèche & 292 & 0.085 & 0.201 & 0.027 & 0.007 & 0.066 & 0.098 & 0.081 & 2 \\
\hline Corsica & 181 & 0.144 & 0.430 & 0 & 0.189 & 0.153 & 0.144 & 0.176 & 5 \\
\hline Dordogne & 91 & 0.144 & 0.413 & 0.498 & 0.278 & 0.467 & 0.503 & 0.384 & 6 \\
\hline Gard & 147 & 0.091 & 0.447 & 0.027 & 0.275 & 0.237 & 0.091 & 0.195 & 3 \\
\hline Lozère & 171 & 0.121 & 0.500 & 0.057 & 0.306 & 0.180 & 0.090 & 0.209 & 4 \\
\hline Languedoc-Roussillon & 114 & 0.068 & 0.415 & 0 & 0.190 & 0.101 & 0.132 & 0.151 & 4 \\
\hline
\end{tabular}

a A locus is considered polymorphic when the frequency of the less common allele is $>0.05$. 
viruses could be used to track the spread of hypoviruses released for BC. Eight of our white isolates of $C$. parasitica from Corsica and Lozère, were studied by this method (1; unpublished data). Seven of them were infected by a hypovirus belonging to the Italian subtype, and one isolate was infected by a hypovirus related to one used for BC in France. This could be due to a lower conversion capacity of the $\mathrm{BC}$ agents than that of other hypovirulent strains $(28,34)$. This finding confirms that the spread of hypovirulent isolates released for BC was low within sites and that the white isolates obtained were mainly due to a natural background level of hypovirulence.

In the coppice forests in Dordogne, hypovirulent isolates were never released, and the background level of hypovirulent isolates found was $5 \%$. In the other regions the percentage of white isolates recovered in sites without $\mathrm{BC}$ may represent the natural background of hypovirulence where $\mathrm{BC}$ is applied. The natural background of hypovirulence was approximately $10 \%$ in Gard and Corsica, 20\% in Ardèche and Languedoc-Roussillon, and 60\% in Lozère. Similar levels of hypovirulence were reported for some areas in Switzerland and Italy where BC was not used $(10,17,23,27)$. Thus, in France, as in other European countries, the spread of white isolates in the field appeared to be linked to factors other than BC. Confirmation of this theory will require further investigation.

The diversity of $C$. parasitica populations was the lowest in Corsica with only six VC types, a Shannon diversity index of 1.11 , and a mean allelic diversity of 0.176 . In contrast, high diversity was found in Dordogne, where we found 14 VC types, $\mathrm{Hs}=2.05$, and a mean allelic diversity of 0.384 . The mean vicallele diversity in Dordogne was higher than in southeastern populations and similar to the values reported for three populations of $C$. parasitica from the United States (36). The structure of $C$. parasitica populations in southeastern regions, where one VC type accounted for 50 to $70 \%$ of the isolates, is expected to strongly favor the transmission of hypoviruses compared to the population structure of Dordogne. At the zonal level, in Ard-5 and LR-2 the most frequent VC type gathered accounted for no more than $39 \%$ of the isolates, which may account for the lower spread of hypovirulent strains in these zones. Within Ardèche, the Shannon index was correlated with the percentage of white isolates, suggesting that the spread of hypovirulence depended on the diversity of the subpopulations. The nature of VC types present in $C$. parasitica may also influence the dissemination of CHV1 in $C$. parasitica populations, because vic- alleles have different effects on virus transmission $(25,36)$. In Dordogne all vic genes were polymorphic, and allelic diversities at loci vic 3 , vic 4 , and vic 7 were higher than in the other populations.

Our results showed that VC-type diversity has decreased since 1981 , i.e., 3 years after BC was used in the regions studied. The frequency of VC-type EU-2 increased significantly in all regions. In orchards the regular release of hypovirulent isolates of $\mathrm{VC}$ types EU-2 and EU-1 is likely to have increased the proportion of these VC types, due to the release of virus-free conidia (41). The spread of the CHV1 could also have resulted in changes in $C$. parasitica populations because of the inhibition of sexual reproduction of the fungus $(3,47)$. However, more information about the mating type ratio and the frequency of fruiting bodies within populations are required to address the role of hypovirulence on the sexual behavior of $C$. parasitica in France. The occurrence of perithecia and the release of ascospores were reported in one orchard (21), but we have no indication of the outcrossing rate of $C$. parasitica in France $(9,35,38)$. Our results showed that in southeastern populations, allele diversities of vic genes were different, and not all vic loci were polymorphic, suggesting nonpanmictic structure of the population, as reported in Italy (30). Sexual reproduction seems to have little influence on VC-type diversity in southeastern $C$. parasitica populations; the most common VC types differed by only one or two vic alleles.
The French (Dordogne) and Spanish western populations of $C$. parasitica (12) appeared different from the populations found in southeastern France, northern and southern Italy, Switzerland, eastern Spain, southeastern Europe, the Republic of Macedonia, Greece, and Bosnia $(14,15,22)$. The differentiation pattern of $C$. parasitica populations in Europe suggests that gene flow between these three different regions of Europe is restricted, and existing populations may reflect founder effects. Differentiation of $C$. parasitica populations could be explained in France, as in eastern North America, by selection or genetic drift (37). However, analyses of vic-allele frequencies did not provide any evidence of selection acting against vic genes (36). On the other hand, European populations are relatively recent and they may not have reached their equilibrium, and it, therefore, is difficult to conclude on an eventual genetic drift. From a previous study, it was concluded that $C$. parasitica was introduced into Europe from Japan or North America (40), not from eastern China. However, the European populations used for this study did not represent all parts of Europe. Some introductions from China might have occurred in western Europe; Chinese chestnuts ( $C$. mollissima) were introduced into France in the Pyrénées at the beginning of the century (43). Such a hypothesis is consistent with the distribution of the different subtypes of CHV1 and with the occurrence of new VC types found in our study in western France.

Our results show that six vic genes with two alleles are not enough to account for all the diversity of $C$. parasitica VC types in Europe. Higher diversity of vic genes has also been observed in China and the United States, where 131 and 67 VC types, respectively, have been reported $(6,46)$. Although most of the American types are compatible with the 64 European testers, only $2 \mathrm{VC}$ types from the 71 found in Japan were compatible with the European testers (13). A seventh vic gene or a third allele in one vic gene may occur in populations of $C$. parasitica in Asia and could have been introduced into western Europe. In France, additional VC types are expected in the Pyrénées, where isolates incompatible with the VC types were observed in the southeastern regions (19). The VC-type diversity of $C$. parasitica populations and their differentiation pattern indicate that adherence to quarantine regulations is essential not only to prevent the initiation of new blight canker foci, but also to avoid any increase in diversity in existing populations by introducing new vic alleles.

\section{ACKNOWLEDGMENTS}

This study was financially and technically supported by the Département Santé des Forêts, the Chambre d'Agriculture de Corse du Sud, the Chambre d'Agriculture d'Ardèche, the Chambre d'Agriculture de Lozère, l'Union Languedoc-Roussillon des Associations Castanéicoles, and the Fédération de Défense des Cultures d'Aquitaine. Thanks to all of the people who contributed to this study. We particularly thank S. Anagnostakis, M. L. Desprez-Loustau, A. Giraud, M. Milgroom, and anonymous reviewers for their helpful comments on an earlier draft.

\section{LITERATURE CITED}

1. Allemann, C., Hoegger, P., Heiniger, U., and Rigling, D. 1999. Genetic variation of Cryphonectria hypoviruses (CHV1) in Europe, assessed using RFLP markers. Mol. Ecol. 8:843-854.

2. Anagnostakis, S. L. 1977. Vegetative compatibility in Endothia parasitica. Exp. Mycol. 1:306-316.

3. Anagnostakis, S. L. 1984. The mycelial biology of Endothia parasitica. I. Nuclear and cytoplasmic genes that determine morphology and virulence in the ecology and physiology of the fungal mycelium. Pages 353-366 in: The ecology and physiology of the fungal mycelium. D. H. Hjennings and A. D. M. Rayner, eds. Cambridge University Press, Cambridge.

4. Anagnostakis, S. L. 1987. Chestnut blight: The classical problem of an introduced pathogen. Mycologia 79:23-37.

5. Anagnostakis, S. L. 1988. Cryphonectria parasitica, cause of chestnut blight. Adv. Plant Pathol. 6:123-136. 
6. Anagnostakis, S. L., Hau, B., and Kranz, J. 1986. Diversity of vegetative compatibility groups of Cryphonectria parasitica in Connecticut and Europe. Plant Dis. 70:536-538.

7. Bisiach, M., De Martino, A., Gobbi, E., Intropido, M., and Vegetti, G. 1988. Studies on chestnut blight: Activity report. Riv. Patol. Veg., 24:313.

8. Bisiach, M., De Martino, A., Intropido, M., and Molinari, M. 1991. Nuove esperienze di protezione biologica contro il cancro della corteccia del castagno. Frutticoltura 12:55-58.

9. Bissegger, M., and Milgroom, M. G. 1994. Outcrossing rates of Cryphonectria parasitica in European chestnut (Castanea sativa) forests. Phytopathology 84:1074.

10. Bissegger, M., Rigling, D., and Heiniger, U. 1997. Population structure and disease development of Cryphonectria parasitica in European chestnut forests in the presence of natural hypovirulence. Phytopathology 87:50-59.

11. Choi, G. H., and Nuss, D. L. 1992. A viral gene confers hypovirulenceassociated traits to the chestnut blight fungus. EMBO J. 11:473-477.

12. Colinas, C., and Uscuplic, M. 1998. Cryphonectria parasitica vegetative compatibility (v/c) groups in the northeast Spain. Acta Hortic. 494:495500 .

13. Cortesi, P., and Milgroom, M. G. 1998. Genetics of vegetative incompatibility in Cryphonectria parasitica. Appl. Environ. Microbiol. 64:2988-2994.

14. Cortesi, P., Milgroom, M. G., and Bisiach, M. 1996. Distribution and diversity of vegetative compatibility in subpopulations of Cryphonectria parasitica in Italy. Mycol. Res. $100: 1087-1093$.

15. Cortesi, P., Rigling, D., and Heiniger, U. 1998. Comparison of vegetative types in Italian and Swiss subpopulations of Cryphonectria parasitica. Eur. J. For. Pathol. 28:167-176.

16. Day, P. R., Dodds, J. A., Elliston, J. E., Jaynes, R. A., and Anagnostakis, S. L. 1977. Double-stranded RNA in Endothia parasitica. Phytopathology 67:1393-1396.

17. Garbelotto, M., Frigimelica, G., and Mutto-Accordi, S. 1992. Vegetative compatibility and conversion among isolates of Cryphonectria parasitica from northern Italy. Eur. J. For. Pathol. 22:337-348.

18. Grente, J. 1965. Les formes hypovirulentes d'Endothia parasitica et les espoirs de lutte contre le chancre du châtaignier. C.R. Hebd. Seances Acad. Agric. Fr. 51:1033-1037.

19. Grente, J. 1981. Les variants hypovirulents de l'Endothia parasitica et la lutte biologique contre le châtaignier. Ph.D. thesis. Université de Bretagne Occidentale, Brest, France.

20. Grente, J., and Berthelay-Sauret, S. 1978. Biological control of chestnut blight in France. Pages 30-34 i : Proceedings of the American Chestnut Symp. Eds., W. L. MacDonald, F. C. Cech, J. Luchok and C. Smith, eds. West Virginia University, Morgantown.

21. Guérin, L., Bastien, S., and Chauvin, B. 1999. The production and dispersal of ascospores of Cryphonectria parasitica in an orchard in South-Western France. Acta Hortic. 494:473-480.

22. Heiniger, U., Cortesi, P., Robin, C., Colinas, C., Perlerou, C., Rigling, D., Sotirovski, K., Trestic, M., and Uscuplic, M. 1998. Cryphonectria parasitica: Vegetative compatibility groups in Europe. 2nd International Symposium on Chestnut. (Abstr.) G. Salesses, ed.

23. Heiniger, U., and Rigling, D. 1994. Biological control of chestnut blight in Europe. Ann. Rev. Phytopathol. 32:581-599.

24. Hillman, B. I., Fulbright D. W., Nuss, D. L., and Van Alfen, N. K. 1995. Hypoviridae. Pages 261-264 in: Rep. Int. Commit. Taxon. Viruses. F. A. Murphy, C. M. Fauquet, D. H. L. Bishop, S. A. Ghabrial, A. W. Jarvis, G. P. Martelli, M. A. Mayo, and M. D. Summer, eds. Springer-Verlag, New York.

25. Huber, D. H., and Fulbright D. W. 1992. Preliminary investigations on the effect of individual vic genes upon the transmission of dsRNA in Cryphonectria parasitica. Pages 15-19 in: Proc. of the Am. Chestnut
Symp. M. L. Double and W. L. MacDonald, eds. West Virginia University, Morgantown.

26. Hutcheson, K. 1970. A test for comparing diversities based on the Shannon formula. J. Theor. Biol. 29:151-154.

27. Intropido, M., De Martino, A., Pellissier, S., and Bisiach, M. 1993. Incidence of chestnut blight in Aosta Valley. Pages 551-554 in: Proc. Int. Cong. Chestnut. E. Antognozzi, ed.

28. Kuhlman, E. G., Bhattacharyva, H., Nash, B. L., Double, M. L., and MacDonald, W. L. 1984. Identifying hypovirulent isolates of Cryphonectria parasitica with broad conversion capacity. Phytopathology 74:676-682.

29. Lewontin, R. C. 1972. The apportionment of human diversity. Evol. Biol. 6:381-398

30. Liu, Y. C., Cortesi, P., Double, M. L., and Milgroom, M. G. 1996. Diversity and multilocus genetic structure in populations of Cryphonectria parasitica. Phytopathology 86:1344-1351.

31. Liu, Y. C., and Milgroom, M. G. 1996. Correlation between hypovirus transmission and the number of vegetative incompatibility (vic) genes different among isolates from a natural population of Cryphonectria parasitica. Phytopathology 86:79-86.

32. MacDonald, W. L., and Fullbright, D. W. 1991. Biological control of chestnut blight: Use and limitations of transmissible hypovirulence. Plant Dis. 75:656-661.

33. Magurran, A. E. 1983. Ecological Diversity and Its Measurement. University Press, Cambridge. 179 pp.

34. Maresi, G., Giovannetti, L., Ventura, S., and Turchetti, T. 1995. Transmission of hypovirulence agents among some Cryphonectria parasitica strains from Italy. Eur. J. Pathol. 25:191-196.

35. Milgroom, M. G. 1995. Population biology of the chestnut blight fungus, Cryphonectria parasitica. Can. J. Bot. 73(Suppl. 1): 331-319.

36. Milgroom, M. G., and Cortesi P. 1999. Analysis of population structure of the chestnut blight fungus based on vegetative incompatibility genotypes. Proc. Natl. Acad. Sci. 96:10518-10523.

37. Milgroom, M. G., and Lipari, S. E. 1995. Population differentiation in the chestnut blight fungus, Cryphonectria parasitica, in eastern North America. Phytopathology 85:155-160.

38. Milgroom, M. G., Lipari, S. E., Ennos, R. A., and Liu, Y. R. 1993. Estimation of the outcrossing rate in the chestnut blight fungus, Cryphonectria parasitica. Heredity 70:385-392.

39. Milgroom, M. G., MacDonald, W. L., and Double, M. L. 1991. Spatial pattern analysis of vegetative compatibility groups in the chestnut blight fungus, Cryphonectria parasitica. Can. J. Bot. 69:1407-1413.

40. Milgroom, M. G., Wang, K., Zhou, Y., Lipari, S. E., and Kaneko, S. 1996. Intercontinental population structure of the chestnut blight fungus, Cryphonectria parasitica. Mycologia 88:179-190.

41. Nuss, D. L. 1992. Biological control of chestnut blight: an example of virus-mediated attenuation of fungal pathogenis. Microbiol. Oecol. 14:823-838.

42. Powell, W. A. 1995. Vegetative incompatibility and mycelial death of Cryphonectria parasitica detected with a $\mathrm{pH}$ indicator. Mycologia 87:738-741.

43. Schad, C., Solignat, G., Grente, J., and Venot, P. 1952. Recherches sur le châtaignier à la station de Brive. Ann. Amelior. Plantes: 369-458.

44. Van Alfen, N. K. 1982. Biology and potential for disease control of hypovirulence of Endothia parasitica. Ann. Rev. Phytopathol. 20:349-362.

45. Van Alfen, N. K., Jaynes, R. A., Anagnostakis S. L., and Day, P. R. 1975. Chestnut blight: Biological control by transmissible hypovirulence in Endothia parasitica. Science 189:890-891.

46. Wang, K., Shao, J., and Lu, J. 1991. On vegetative compatibility of Cryphonectria parasitica in Jiangsu and Anhiu. J. Nanjing Agric. Univ. 14:44-48.

47. Zhang, L., and Van Alfen, N. K. 1994. Viral suppression of fungal mating-type-specific gene expression. (Abstr.) Phytopathology 84:1075. 